\title{
Building and Validating a Tool for Assessing Academic Writing Skills
}

\author{
Bruria Margolin (Corresponding author) \\ Dept. of Hebrew Language, Levinsky College of Education \\ P.O.Box 48130, Tel-Aviv, Israel
}

Tel: 972-3691-7413 E-mail: bruria.margolin@gmail.com

Drorit Ram

Dept. of English Language, Levinsky College of Education

P.O.Box 48130, Tel-Aviv, Israel

Tel: 972-523-426-534 E-mail: drramar@bezeqint.net

\author{
Rachel Mashiah \\ Language Education in a Multicultural Society, M.Ed. Program \\ P.O.Box 48130, Tel-Aviv, Israel \\ E-mail: rachelmashiah@gmail.com
}

Received: April 8, 2013 Accepted: July 23, 2013 Published: August 30, 2013

doi:10.5296/ijl.v5i4.3498 URL: http://dx.doi.org/10.5296/ijl.v5i4.3498

\begin{abstract}
Most studies that examine the academic writing skills of freshmen students point to a gap between the writing skills of entering freshman students and the requirements of academic writing. This study describes a research tool designed to assess the academic writing skills of entering students. This tool, known as the Test of Academic Writing Skills (TAWS), was developed by breaking down the criteria of academic writing into measurable components that can be explicitly interpreted, thus enabling accurate identification of the weak points in students' academic writing. The results achieved using this tool reinforce the dichotomy
\end{abstract}




\section{Macrothink}

International Journal of Linguistics

ISSN $1948-5425$ 2013, Vol. 5, No. 4

between basic writing skills, including reading comprehension and summarization, and higher-order academic skills involving the synthesis of information. The results also make it possible to assess levels of basic skills and higher-order writing skills.

Keywords: Academic writing, Language skills, Text assessment, Basic writing skills, Higher-order writing skills 


\section{Introduction}

Academic writing, one of the markers of academic literacy, involves writing that integrates synthesis of texts from different sources into one coherent text. The skills required in academic writing include the ability to assess and process information from different sources and the ability to synthesize this information into a new text (Ezer, Margolin \& Sagi, 2009). Research findings point to a strong and direct correlation between students' academic literacy skills and their academic achievements in institutions of higher learning. Academic writing skills are among the best predictors of success during the freshman year of college or university (Cohen-Gross, 2003).

Despite evidence pointing to the importance of academic writing, most research in Israel, North America and Europe (Beaufort, 2007; Dubarry, 2008; Folman, 1994; Hazlett, 2008; Margolin \& Ezer, 2008; Sarig, 1997; Segev-Miller, 1999; Steinway; 2008) that has examined the academic writing skills of freshmen students points to the gap between the writing skills of entering freshman students and the requirements of academic writing. The primary cause of this gap is that the writing assignments given by most teachers in high school do not prepare students for the type of writing required in higher education and rarely involve analysis and interpretation (Kiuhara, Graham \& Hawken, 2009). The difference between high school writing assignments and the type of writing required in college and university stems mainly from differences in outlook between high school and college teachers regarding the type of writing skills they expect their students to use. According to the results of a study in the United States (Steinway, 2008), only 6\% of university lecturers teaching academic writing believe that their students are proficient in academic writing skills, compared to $36 \%$ of high school writing teachers. This study also found that $44 \%$ of the academic faculty in various university departments in the US believe that students are not prepared to write on the level required by institutions of higher education.

Some believe the "blame" for students' difficulties with academic writing should not be attributed to the level of high school studies or to unsuitable curricula, but rather mainly to Internet use (Dubarry, 2008). While in the past students read journals and research books and were exposed to the norms of writing customary in the world of academia, in the Internet era, they "cut and paste" texts, and this has had a negative impact on their language skills. They make mistakes in spelling and grammar, and some lack proficiency in reading comprehension and essay writing. Thus, institutions of higher education must teach students basic academic skills.

The gap between students' writing skills and academic requirements is also apparent in Europe (Lee, 1994). At the University of Glasgow and the University of Edinburgh, local students as well as those from other places experience difficulties in writing. Students pursuing bachelor's degrees (Hilsdon, 2004) admitted that their writing skills could use some improvement, and their teachers agreed. The problem is not only in spelling and grammar, but mainly in developing an argument, providing evidence, making references and choosing the proper style and register. Another study (Ganobscik-Williams, 2004) identified 64 different writing tasks in the various genres students were required to write during their 
studies, among them theoretical essays, reports, answers to examination questions, posts on online discussions and forums, electronic portfolios, e-mail and website content. In all of these, students experienced difficulties expressing themselves.

In Israel the democratization of higher education created a situation in which college and universities began accepting students on a lower academic level than previously. In the past a student's academic level was a requirement for admission, but today this is not the case (Ezer, Margolin \& Sagi, 2009). Research examining students' knowledge of academic writing at the end of their freshman year indicates that even beginning writers without any learning disabilities have difficulty coping with academic writing assignments and that their writing is not up to par (Margolin \& Ezer, 2008). In view of these findings, institutions of higher education are aware of the need to develop students' academic writing skills during the course of their academic studies.

\section{Academic Writing Skills Required by Institutions of Higher Education}

Over the past thirty years, studies on literacy have revealed disagreement among researchers with respect to the academic writing skills required for higher education. Some claim (Flower, 1989) that the skills required are those based on general knowledge in problem solving, while others (Smagorinsky \& Smith, 1992) distinguish between general problem solving knowledge and command of specific writing skills. According to these, general knowledge includes grammar, vocabulary, spelling, writing planning, discourse genres and mental schemes regarding the writing process. Specific knowledge comprises content, relevant vocabulary, knowledge of syntax, an action plan in the social context of writing and a command of problem-solving processes.

Proficiency in academic writing skills involves the ability to read and write in accordance with the principles of theoretical academic discourse along with the ability to process texts according to the two main components of discourse: cohesion and coherence. A distinction is often made between the overt textual features of a discourse-i.e., cohesion-and its covert features-coherence (e.g., Margolin, 2012; Tanskanen, 2006;). Cohesion helps in inserting ideas into a sentence and in creating links between ideas in different sentences and between paragraphs (Scardamalia, Bereiter \& Goelman, 1982). Coherence deals with associated meanings on the semantic and more global level of the text (Margolin, 2012).

Halliday and Hasan (1976) set down the methodological foundations for the term cohesion. They defined the term as the overt linguistic devices the author uses to produce a textual continuum. According to them, these devices can be classified into five groups: reference, substitution, ellipsis, lexical cohesion and conjunctions. Many researchers agree in principle on the methodological importance of Halliday and Hasan's model of cohesion (Tanskanen, 2006), and use this model when examining cohesion in a text (e.g., Connor, 1984; Shen, 2010). In this study as well, we use Halliday and Hasan's model of cohesion to examine textual cohesion.

The term coherence has numerous definitions. The simplest definition of discourse coherence is that "discourse as a sequence of propositions is coherent if facts (events, actions, situations) 
it refers to are related" (Van Dijk, 2008: 185). That is, a discourse is coherent for language users if they are able to construct a mental model for it (Van Dijk and Kintsch, 1983).

In addition to being proficient in the principles of theoretical academic discourse and able to clarify ideas (Bar-Asher, 2012) and present them in a critical fashion, skilled writers must also be able to let their own voices be heard (Ezer \& Ram, 1999; Zhao \& Llosa, 2008). The writer's individual voice is expressed not only by stating a position vis à vis the text but also by processing the text.

One of the most important skills in theoretical academic discourse is the ability to present and develop an argument (Hauftman, Rosenfeld \& Tamir, 1999; Rafaeli, 1996; Sarel, 1997). The roles of formal writing for an argumentative text distinguish between two types of skills: (1) those related to the text as a whole in the sense of presenting the arguments and points, being proficient in the use of connective devices and differentiating between what is primary and what is secondary; and (2) those related to more specific aspects of the identification and use of technical means, such as exemplification and the use of words with a higher academic and theoretical register. The ability to develop an argument marks theoretical writing and serves as the basis for theoretical texts, with the argument itself constituting the main idea and the essence of the text (Margolin \& Ezer, 2008).

The skills required to develop an argumentative text include description, explanation, proof, citation, comparison and definition. Identifying examples is also an important skill, for one of the ways to develop the main idea and prove the argument is through example (Shilo, 2003). The production of an academic text is considered to be the most complex task in the hierarchy of literacy tasks: The writer is required to read many texts, select and organize information from various sources and process all of this in order to produce an academic text and present it as an original synthesis. Through this integrated written text, the writer creates a new body of knowledge (Hauftman, Rosenfeld \& Tamir, 1999; Ezer, 2002).

Skilled writers use categorization to distinguish between what is important and what is not, and they identify organization and cohesion patterns to understand the associations among the units of knowledge. These constitute the higher-order skill of academic writing, a form of writing that integrates the ideas the writer needs to demonstrate proficiency in synthesizing information from a variety of literary sources. This skill differs from the writing of summaries of texts or ideas, which is a basic skill of academic writing applied to a single text (Folman, 1997).

The task of synthesizing information requires readers/writers to convert the text by means of what is known as conceptual conversion. That is, writers must disengage themselves from the concepts of the text being read (source text concepts) and instead formulate the concepts of the new text they are writing in accordance with the topic they are developing (target text concepts). Writers must coordinate a large amount of knowledge collected from numerous sources around the target text concepts. This knowledge must be implemented in accordance with the target text, including presentation of the topic based on personal experience and coherent conceptual argumentation (Brig, 1994). This writing task takes place at the micro-text level, the level of general overview of the textual discourse that transcends the 
pieces of information collected in the individual propositions, paragraphs and sections. This level of reading-writing requires readers/writers to invest a great deal of mental effort, which is expressed by creating a high level and coherent conceptual structure that is common to all the synthesized sources and transcends the topical exclusivity of each individual text.

Hauftman, Rosenfeld and Tamir (1999) defined the profile of a reader/writer with a high level of literacy and the profile of a reader/writer with a low level of literacy. A highly literate reader is able to cope with articles that are unclear and to develop strategies for coping with the difficulty. This type of reader locates relevant information from a variety of sources, reads in depth and superficially, is assisted by titles and subtitles, identifies repeated ideas from several sources and summarizes them, marks the text and makes comments. This skilled reader looks for signs of cohesion among different opinions. When such a reader writes, he or she presents specific units of knowledge while giving complete and accurate citations, puts forward the argument and organizes the relevant units of knowledge around it. Moreover, the writing of skilled students uses the linguistic register appropriate to formal Hebrew, makes proper use of conjunctions and prepositions (Shilo, 2003) and exhibits a high degree of cohesion and coherence. In contrast, a reader/writer who is less skilled relies on précises and summaries and inserts these sequentially by adding connective words, so that the degree of textual cohesion and coherence is low. The profile of a literate reader/writer should also include the following dimensions: use of general and local structure and organization, compliance to linguistic standards (linguistic form, syntax and grammar), communicativeness (degree to which the writer is aware of the reader) and individual voice (Brosh-Weitz, 1999).

\section{Tools for Assessing Students' Academic Writing}

Holistic assessment of writing products was popular in the 1970s and is still popular in the assessment of short writing samples (Hamp-Lyons, 1991). Based on certain guidelines, the assessors assign a score reflecting their impression of the text. In recent years most research studies in the area of writing assessment have focused on evaluating writing in a second language and have attempted to design assessment tools that are less based upon impression. These studies of writing in a second language (Kroll, 1998; Knoch, 2008) indicate that an assessment scheme based on many factors has advantages over assessment based upon impression. Such a scheme has greater validity than tools based on impression and is more reliable regarding the diagnostic information given to the writer and the teacher. One such scheme for assessing writing in a second language included four main components. The first, focus on the essence or the main point, refers to the content of the text, the way in which the main ideas are presented and the explanations and arguments given. The second component refers to how the text is organized and examines whether the text has a structure of beginning, middle and end. The third component is the use of language, including the use of abstract utterances, idioms and expressions in the second language, the linguistic level of the text and the linguistic register. The fourth component refers to the rules of writing. Each of these components can be assigned a score ranging from 1 to 9 (Hamp-Lyons's 9-point scale, in Hamp-Lyons, 1991). Another study (Sufumin, 2002) proposed examining the text as it was written, without correcting grammatical errors. 


\section{Mll Macrothink}

International Journal of Linguistics

ISSN 1948-5425

2013, Vol. 5, No. 4

One of the commonly used tools for examining the knowledge of freshman students regarding academic writing is the Calp test, used to examine expressive ability among freshman students (Kroll, 1979). This test examines linguistic and grammatical components, formal and informal writing genres and limited analysis and interpretation of prose and poetry. The test is based on the assumption that students know the basic rhetorical principles and are capable of implementing the principles of standard writing. The Calp test requires familiarity with research articles and citation skills. In one part of the test students are required to respond in writing to two topics and to demonstrate their ability to write clearly and effectively. The test is 90 minutes in duration, during which time the students must answer 90 questions. Of these, $20 \%$ are used to measure students' awareness of a variety of grammatical, structural and logical relations in the sentences of the examination text, $65 \%$ of the questions assess the ability to identify logical development and organizational connections of coherence and cohesion in a theoretical text, and 15\% examine the ability to make proper references to the literature and to use the rules of citation.

The Calp test is not suitable for assessing the writing skills of students entering colleges and universities in Israel for several reasons. First, it was developed for an English-speaking population and is not up to date. It also requires previous knowledge about research articles and a command of reference skills, which first-year students in Israel have not yet learned. Moreover, it examines open writing about two topics rather than writing that integrates information from at least two sources. Nevertheless, in developing the research tool proposed here, we adopted the format of a two-section test-the first containing questions to be answered and the second a writing task-due to its suitability for testing the basic skills of academic writing.

Another tool used to assess texts is the Coh-Metrix tool (Graesser, McNamara, Louwerse \& Cai, 2004). This computerized tool analyzes texts automatically and yields a variety of linguistic indicators. It is used mainly to examine five measures that predict the quality of a text. Two of these measures include sub-measures that examine cohesion (references and connectors), and three include sub-measures pointing to linguistic finesse, general knowledge and language and discourse features. Despite the accuracy in measuring these qualities by means of the computer, it is not clear how this can be used to assess the quality of the content. Some claim (McNamara, Louwerse, McCarthy, \& Graesser, 2010) that this tool identifies the cohesion in a text and differentiates between texts scoring high on syntactic complexity and those scoring low, accomplishing this by counting the number of words preceding the main verb and by the sentence structure, as well as by means of vocabulary variety (using parameters of frequency, concreteness and imagination). Validation of the Coh-Metrix tool revealed that the indicators best predicting textual quality are those related to syntactic complexity and to vocabulary. In contrast, an examination according to the Coh-Metrix's 26 measures of cohesion did not reveal differences between high-level and low-level texts.

Studies conducted in Israel (Margolin \& Ezer, 2008; Yarchi, 2001) have developed criteria for assessing academic writing. The criteria for academic writing assessment developed by Yarchi (2001) are as follows: content structure, content originality, content accuracy, logical consistency, division and transitions, use of logical and rhetorical connections in higher level 
discourse, discourse genre, statement of the topic, argument structure, support for the argument, integration of topics and argument, higher-order rhetorical structure, argument coherence and links, topic analysis, word choice and wording and use of academic lexis. The study by Margolin and Ezer (2008) examined students' ability to write an argumentative essay according to four general measures of writing quality: content, structure, syntax and style. In the current study we used highly explicit criteria with respect to content, connectors, argument structure and support for the argument, coherence, structure of the text and syntax, and appropriate choice of lexis. Some of these were broken down into measurable components, as described below and in Appendix 2.

\section{Research Description}

The primary objective of this study is to assess the academic writing skills of entering freshman students. The study variables are the basic skills and the higher-order skills of academic writing. The basic skills are related to sentence grammar, to the development of a single idea, to summarization and to generating paragraph cohesion. The higher-order skills require the organization and reorganization of ideas, the generation of a new text where ideas from a number of texts are synthesized, the generation of connectors between ideas and paragraphs in the text and the use of the conventions of academic writing, including references.

\subsection{The Research Tool}

A test of academic writing skills (TAWS) was developed as the research tool to examine the research variables. The tool was developed in three stages.

Stage 1 comprised choosing three texts for the reading and writing tasks. The texts were chosen based on the following considerations: grammatical textual complexity, compatibility with the academic writing genre (theoretical text on an academic topic) and length. The researchers aimed at choosing readable and clear texts on a theoretical academic topic whose length was suitable to a 90-minute test, so that students would have enough time to do the reading and writing tasks during one academic lesson. The chosen texts center on the issue of Jewish identity rooted in the broader philosophical and sociolinguistic context of identity, making them relevant to Jewish as well as non-Jewish students.

Stage 2 involved determining the higher-order skills and the basic skills to be assessed by the exam, in accordance with the higher-order and basic skills outlined in discourse theory. The skills assessed by the TAWS are: 1) identifying the main idea (Question 1);2) distinguishing what is of primary importance from what is secondary (Question 2); identifying examples (Question 3); 4) identifying connecting words in the text (Question 4); 5) paraphrase writing (Question 5); 6) writing a short summary as a paraphrase (Question 5); 7) identifying the types of connectors in the text (Question 6); 8) integrated writing (Question 7); 9) writing using references (Question 7). Skills 1-6 are basic skills, and skills 7-9 are higher-order skills.

Stage 3 included composing tasks (Appendix 1, TAWS) suitable to test the above skills. For each skill a performance task was devised that could be used to assess to what degree the student successfully performed the task. 
As a test of internal validity, two colleagues who teach academic writing to freshman students were given a copy of the test and asked to determine to what degree the test examined proficiency in the skills of academic writing. The experts submitted comments and additions regarding how the test tasks should be formulated. Based on these, two of the tasks were reformulated to make it clear to the students which tasks required that they use their own words and which required that they copy words or sections from the text.

The tool is based upon the notion that literacy is a tapestry of skills that are acquired hierarchically. According to this approach, texts are assessed in a hierarchical manner, so that if the content is not correct, no reference is made to the other elements of writing and language, such as grammar and style. The acquisition of any particular skill has no bias or prerequisites. Moreover, there is no deviation in the research tool, and all the elements are broken down into factors.

The research tool was not developed ex nihilo. The principles underlying the research tool are based on prior research. 1) In the current study, students are given texts and asked to read and refer to them. This structure is based on a tool developed by Cushing (2004), which was adopted in developing the tool for this study. 2) The current tool is based on an exam with a two-part structure: the first part with questions to be answered and the second part with writing tasks to be carried out. This format is typical of the Calp test (Kroll, 1979) and was adopted in developing the current research tool. 3) Students' writing ability in the current test is examined by parameters of structure, content, syntax and style. These parameters have been used in previous studies (Margolin \& Ezer, 2008). In the current study we refer to these four parameters, but the tool we developed is more explicit because the four parameters were broken down into measurable components (Appendix 2). This breakdown into measurable components aids in evaluating the basic skills as well as the higher-order skills. Its major contribution is in the summarization and integration tasks where we used a large number of measurable components. For example, in assessing vocabulary we referred only to academic words. To this end we were aided by the Academic Word List (AWL) in English (Coxhead, 2000) and by the list of academic words prepared by Brosh (1996).

\subsection{Research Procedure}

The study was conducted in three stages. In the first stage, the researchers constructed a tool for measuring the writing skills of students in their first year of college: a Test of Academic Writing Skills (TAWS). The test was amended in view of the comments of two experts in the field of teaching academic writing. After that the test was evaluated by two judges, with $95 \%$ inter-rater agreement. A discussion was held to determine how to reach $100 \%$ agreement. For the sake of validation and reliability testing, the test was administered to one group of participants (a class taught by one of the researchers). Based upon this, we determined the analysis categories. In effect, these a priori categories are the skills to be assessed (the nine skills outlined above), which were validated by two judges who examined three tests from the sample. In these three tests, the judges examined the validity of the statements, the degree to which the respondents understood the various statements and the reliability of the writing. The judges were asked to assign a score for these criteria. The categories deemed problematic 
were then discussed, and new categories were determined instead. The tool was revised and again given to two judges for validation and to ten additional respondents for assessing inter-rater reliability, to eliminate deviations in the stage when each lecturer would be asked to check the tests of his or her students. After the analysis categories were agreed upon, the three tests were again examined by the two judges and by the researchers. The results were compared and discussed until agreement was reached on how to use the categories for assessment (see Appendix 2, encoding based on the TAWS analysis criteria).

In the second stage, the TAWS tool was assessed in a pilot study conducted in the second semester of the 2008-09 academic year in six classes (around 140 students). Based on the results of this study, the research tool was improved, as follows: 1) The test was shortened. The test used to assess academic writing skills was shortened because in the pilot study students had difficulty completing it and did not reach the point of demonstrating higher-order writing skills. If they did reach that point, they were no longer motivated or not focused. Both the texts and the questionnaire were shortened. 2) The tasks assessing reading comprehension skills were simplified. The students were asked to identify the answers to the first questions and to copy them, rather than to paraphrase. This simplification helped to clearly separate the reading comprehension tasks from the writing tasks (summarization and integration). Prior to this revision, the reading comprehension tasks were found to include requirements for higher-order thinking, for example paraphrasing. 3) A task was added in preparation for the higher-order skill of synthesizing texts. We added a task to prepare students for integrating texts. In this new task, students were asked to determine the logical relations among three texts. In this way, we created a tool in which all the tasks preceding summarization (intermediary task) and integration (higher-order task) were a preparation for the subsequent tasks. The basic tasks examined basic skills while at the same time preparing the writer for the tasks examining the higher-order skills. 4) The assessment tool was improved. One of the objectives of our research was to create a hierarchic tool with measurable parameters to be used to determine the literacy abilities of writers. Coincident with developing this tool, we also developed an assessment key and set out clear, focused and unequivocal criteria that can be validated, are not at all dependent upon impressions and are not biased.

In the third and final stage, the test was administered to all the students participating in the study. It was then examined by the researchers and by a research assistant who is not an expert in this field of knowledge. All the answers to the last question, the synthesis question, were reexamined by one of the researchers to validate the research assistant's assessment. The results of these assessments were identical, so that $100 \%$ inter-rater agreement was achieved.

\subsection{Data Analysis}

The data were coded as follows. Attached to each test questionnaire was a coding form with a scale from 1 to 4 to assess performance according to the following assessment key: lack of performance, defective performance, low level performance, intermediate level performance and high level performance. This is a semantic differential scale (Cohen, Manion \& Morrison, 2007) in which one adjective is at one extreme of the scale and its bi-polar opposite is at the 
other (e.g., very much :4; not at all: 1 ).

SPSSX statistical analyses were used to examine averages, and frequencies and comparisons were analyzed by t-tests between groups of students with different majors, for each of the skill measures separately and all of them together. This made it possible to determine the number of students who are proficient in each of the writing skills examined and to compare this to the number of students who are more proficient or not at all proficient in a particular skill. It also enabled us to compare each skill among students from different majors. This analysis also made it possible to point to students' degree of proficiency for each of the skills and to differentiate between proficiency on basic skills and proficiency on higher-order skills.

\subsection{Research Population}

The research population comprised 203 students at a teacher education college in the center of Israel. All participants were new students in their first year of studies. They differed in place of birth, mother tongue, major area of study and eligibility for accommodations on tests due to learning disability diagnoses. Ten percent of the participants were men and the rest were women.

Around $85 \%$ of the participants were born in Israel, $8 \%$ in Russia, 1.5\% in England, $1 \%$ in Ethiopia, $1 \%$ in the United States and $3.5 \%$ in other places. Hebrew is the mother tongue of $80 \%$ of the students, with Russian the mother tongue of $6.5 \%$, Arabic of $6.5 \%$ and the rest with some other mother tongue.

With respect to major area of study, $22 \%$ were early childhood education majors, $22 \%$ elementary school education majors, $7.5 \%$ high school education majors, $13 \%$ special education majors, $15 \%$ special education with another major, $11 \%$ music education majors and $1.5 \%$ English teaching majors. The remainder studied in other programs. Around $7.5 \%$ of the participants were in a special excellence track, and around $20 \%$ were eligible for test accommodations due to diagnoses of learning disabilities. All the students had successfully completed their high school matriculation exams, including the Hebrew language exam, and all exhibited their proficiency in reading and writing Hebrew on their college entrance exams and on the Psychometric Entrance Test (PET). The Arab students passed the 5-unit matriculation exam in Hebrew and had a good command of Hebrew. Students identified as new immigrants were not included in the research population because they study in a special program during their first year of college.

\section{Research Findings}

The findings refer to student performance on the three main skills examined: reading comprehension skills, summarization skills and skills in merging information. The data were analyzed using SPSSX software.

\subsection{Reading Comprehension Skills}

Participants' proficiency on reading comprehension skills was measured by their ability to extract relevant information from a text ( $q 1$ and $q 2$, Appendix 1), to refer to examples (q3, Appendix 1) and to identify connectors (q4, Appendix 1). The initial hypothesis was that all 
students would demonstrate good performance on these tasks since they studied and practiced these skills as part of the language arts curriculum in elementary school and the Hebrew studies curriculum in high school (Ministry of Education, 2005).

The first task was identifying the main idea in the text and copying it (q1, Appendix 1). Around $22 \%$ of the students identified the main idea in its entirety, while $60 \%$ identified it but not completely. The conclusion based on these findings is that approximately $80 \%$ of the students are proficient this skill.

On the task of identifying additional important ideas in the text, students demonstrated a relatively low level of performance (q2, Appendix 1). Only $13 \%$ of the students were able to perform this task perfectly, and around 5\% managed to identify additional important ideas, but not completely. That is, fewer than $20 \%$ of the students demonstrated proficiency in the skill of identifying additional important ideas in the text.

The students demonstrated good proficiency in identifying and citing examples in the text (q3, Appendix 1), with $18 \%$ performing this task completely and $60 \%$ citing the example but not in its entirety. Nevertheless, the students were not precise in their use of proper punctuation. Only $7 \%$ punctuated correctly, and $12 \%$ were almost correct in their use of punctuation. The remaining $80 \%$ did not pay any attention to proper punctuation.

Half of the students demonstrated a good ability to identify connecting words in the text (q4, Appendix 1). Of these, 5\% performed the task perfectly and around $40 \%$ had almost perfect identification. No significant differences in performance on these tasks were found between native speakers of Hebrew and those with another language as their mother tongue, or between students diagnosed with learning disabilities and the rest of the students.

In summary, students' proficiency in reading comprehension skills can be divided into two: skills on which students demonstrated a relative degree of proficiency and skills on which they did not demonstrate any proficiency. Students demonstrated proficiency in identifying the main idea (80\%) and in citing an example from the text $(78 \%)$. These tasks are related to content and information processing. In contrast, they did not demonstrate good proficiency on an additional task related to content and information processing. Only 38\% were able to identify important ideas in addition to the main idea. The students exhibited less proficiency on the technical skills of identifying connectors (only $45 \%$ succeeded) and using punctuation (only 20\% succeeded). No significant differences in performance of these skills were found between native speakers of Hebrew and those with another language as their mother tongue, or between students pursuing different majors, or even between those diagnosed with learning disabilities and the rest of the students.

\subsection{Summarization Skills}

Summarization skills were measured by a number of parameters, the most important of which is paraphrasing. The ability to write a paraphrase is of prime importance because it points to the relation between understanding the main ideas and the ability to reiterate them in the writer's own words. It also testifies to the ability to process the text. Copying sections of the text verbatim reflects a lack of reorganization and independent processing skills. Moreover, 
verbatim copying does not necessarily reflect the writer's understanding of the text. In this study, paraphrasing was defined as a necessary condition in the hierarchy of tasks. Hence, a summary containing exact or almost exact (90\%) copies of two or more sentences constituted a failure to perform the task. That is, not fulfilling the necessary condition of writing a paraphrase resulted in a failing score on the entire task. Giving an answer that is not relevant (i.e., does not refer to the content of the text) also resulted in a failing score.

The summarization task was also examined according to attributes of format, content and linguistic style. With respect to format, we examined the concluding paragraph in accordance with the technique of writing a number of sentences in a single block. For content, we examined coherence and cohesion. To meet the coherence parameter, the conclusion had to include a statement of the main idea in a single sentence, together with at least two supporting sentences expanding the main idea and expressing agreement, disagreement or reservations. Cohesion was examined through the use of anaphora (The use of linguistic unit, such as a pronoun, to refer to another unit), precise repetition of words and substitution of words with another word that is not a pronoun. Style referred to the use of register appropriate to written language, without slang, the use of academic words and the use of appropriate logical semantic connectors. Syntax was also examined through the presence of a subject and predicate, proper use of prepositions and syntactical agreement. Spelling was evaluated according to the number of spelling mistakes in the text, while punctuation was assessed by the presence of a period at the end of the sentence and the use of quotation marks when quoting directly from the original text.

Summarization is more difficult than identifying ideas and or reading comprehension because it requires both reading comprehension (a basic requirement) and the ability to process, reorganize and reword a text. Rewording requires a good command of language, syntactic components, grammar, spelling and punctuation. Nevertheless, we hypothesized that students would demonstrate proficiency on this skill because they had practiced it in high school as part of the Hebrew studies curriculum (Ministry of Education, 2005). Question 5 (Appendix 1) asked the students to summarize one of the texts they read using their own words. Their performance on this task was on a high level. They maintained the format and summarized the main ideas in the article in their own words so that the message was clear.

Specifically, $88 \%$ of the students performed the task perfectly from the perspective of format, while the performance of another $6 \%$ was almost perfect $(6 \%)$ in that they wrote a complete paragraph. With respect to content, $71 \%$ of the students wrote a coherent text with a main idea and supporting sentences expressing reservations, agreement or disagreement with the idea, and another $17 \%$ wrote a text with satisfactory coherence. For the parameter of cohesion as well, the students generally showed their proficiency and used pronouns and varied connective devices. Around $70 \%$ did so perfectly, and another $18 \%$ demonstrated a good command, with only one mistake. With respect to style, students' use of language register suitable for academic writing was usually good. Although only $10 \%$ demonstrated perfect use of appropriate register, most (70\%) showed a good command and usage of the proper register, practically without mistakes. For the most part students used correct syntax in their texts, with $40 \%$ demonstrating perfect usage and $40 \%$ with only one mistake in syntax. The 
students also were punctilious in their spelling, with $62 \%$ not making any spelling mistakes and $23 \%$ with only one mistake. With respect to punctuation, $67 \%$ had perfect punctuation and another $24 \%$ had only one error in punctuation.

\subsection{Skills in Merging Information}

The most complex skills are in merging information from a number of sources (texts). This task requires identifying global logical connections among ideas and arguments in different texts, that is, the meta-textual ability to create a synthesis of ideas and to present it in practice by writing a merged text that explicitly puts forward these connections. Students were assigned two tasks that assessed these skills. One was a preliminary task involving identification of logical connections among ideas from the various texts they read. The other was a performance task involving merging ideas from the texts they read into a monolithic text written in their own words. We assumed that the students had previous experience in writing summaries and arguments, but not necessarily in merging information from a number of sources, a task usually identified with academic studies. Therefore, they were given a preliminary task (see q6, Appendix 1) whose goal was to direct them toward identifying the ideas common to the texts. Only after they carried out this identification task would they begin the writing task, and they could use the connections they identified in writing the merged text (q7, Appendix 1). In the preliminary task, the students were asked to identify three types of relationships between ideas in the texts, such as contradictions or additions.

Student performance on this task can be divided into two: the quality of basic writing skills and the quality of higher-order writing skills. These higher-order skills include creating ties between ideas and expressing these ties in a written text, as well as merging information, as seen in writing a comprehensive idea that unites the texts, expanding the idea and providing explanations and examples. On the task requiring information merging, the students demonstrated their ability in aspects relating to format and style, as well as other linguistic aspects such as correct language and syntax. Nevertheless, they had difficulty writing a coherent text and making explicit the relations among ideas from the different texts, as described below.

\subsubsection{Student performance on Basic Skills in Text Merging Information from Three Sources}

On format, most of the students $(71 \%)$ were able to write a number of sentences in sequence to create a paragraph, with $20 \%$ doing so close to the required level though not accurately. Only $11 \%$ did not manage to write the required paragraph. With respect to cohesion of the merged paragraph, most of the students made satisfactory use of cohesive devices such as anaphora and word substitution. Of these, $27 \%$ made use of at least three cohesive devices, while $56 \%$ used two such devices. Only $17 \%$ used one cohesive device or did not use such devices at all. The students also demonstrated relatively good proficiency with respect to writing style, with $30 \%$ using academic writing style, including words from the academic genre. Around 50\% used academic words in their writing but did not maintain a high linguistic register and used slang. Thirty percent used language appropriate for written texts but did not use academic words or used language inappropriate for written texts together with slang. On the parameter of syntactical correctness, measured by sentences containing a 
subject and predicate, the use of prepositions and syntactical agreement, $30 \%$ of the students were completely accurate, another $38 \%$ performed at a satisfactory level, $18 \%$ had partial success and $15 \%$ did not use correct syntax. On spelling, more than half the students $(53 \%)$ did not make any spelling mistakes, $27 \%$ had one spelling mistake and $20 \%$ had two or more spelling mistakes. On punctuation (period at the end of a sentence and use of quotation marks for a direct quote), more than half the students (53\%) made no mistakes, 26\% made one mistake and $16 \%$ made two or more mistakes in punctuation. The students did not demonstrate proficiency in referring to sources according to the conventions of academic writing. Only $1 \%$ were correct and consistent in citing all the references, while $50 \%$ cited references but not correctly and not consistently, and the rest cited only partially or did not use citations at all.

In summary, for the basic skills used to merge information from three sources students' performance was generally good, with the exception of citation, an academic skill that was evidently new to most of them.

5.3.2 Student Performance on Higher-Order Skills in a Text Merging Information from Three Sources

Only $3.5 \%$ of the students were able to find three connections among the ideas in the three texts they read, $35 \%$ found two of the three connections, $40 \%$ found one, and $22 \%$ did not find any connections or did not answer the question.

Around $10 \%$ of the students succeeded in writing a topic sentence at the beginning of the merged paragraph. Following are several examples taken from the answers to q7 (Appendix 1), merging information. "In effect, who is a Jew? Who deserves to be referred to as Jewish? These questions are approached in numerous ways" (questionnaire 2); "The question of who is a Jew has more than one answer. On the one hand is the definition..." (questionnaire 37); "There are two approaches to being a Jew. According to one, a Jew is someone who considers himself Jewish..." (questionnaire 30). Another $11 \%$ of the students wrote an incomplete topic sentence. The following is an example of a topic sentence that merges two ideas from two articles, but not from three: "Amos Oz and A.B. Yehoshua both consider being a Jew to be a choice made by the individual" (questionnaire 25). An unsuccessful attempt to write such a sentence was made by $25 \%$ of the students, while $54 \%$ did not write any sort of topic sentence.

An additional higher-order skill that was not demonstrated very frequently was the skill of writing a merged paragraph that expressed the conceptual ties among the three texts. In the merged texts, $14 \%$ of the students gave expression to the conceptual ties, explained them and gave examples, while $25 \%$ managed to tie between two ideas and expressed this in the merged text. Another $15 \%$ attempted to do this but the connection between the ideas was not clear and no examples were given. Almost half the students (46\%) did not do this task at all.

Only seven students, $3.5 \%$ of all the participants, identified connections or relations among the ideas from the three texts, and only five of these managed to express these relations in the content of the merged paragraph they wrote. One did not merge the ideas at all. Another 
merged them incorrectly from the perspective of content by incorrectly expressing a relationship of contrast rather than of addition.

The above findings indicate that the level of higher-order skills in the students' texts merging information from three sources did not meet the requirements of academic writing, which necessitates the merging of information from a number of sources into a new text.

\section{Discussion}

According to the literature, the gap between the academic literacy skills of entering freshman students and what is required of them for academic studies is a worldwide problem. Yet no appropriate solution has been proposed to bridge this gap. The current study therefore has practical importance in two areas. First, the research tool proposed here for assessing the initial academic skills of entering students is important and relevant for all institutions of higher education in Israel. Moreover, this test can serve as the basis for constructing a similar assessment tool for institutions of higher learning abroad. The literature on assessing academic writing skills revealed that measurement tools are lacking. Those tools that have been developed are not up to date, and institutions of higher learning do not have a uniform means of assessing students' skills in their first year of studies. The second practical implication of this study lies in its contribution to the development of a curriculum for academic literacy. Such a curriculum can be designed to more accurately bridge the gap between students' academic reading and writing skills in general, and those of each student individually, and what is expected of them in this area. The findings uncovered using the tool developed for this study reinforce the diagnosis of a dichotomy between basic writing skills, including reading comprehension and summarization, which most students have, and higher-order academic skills related to the assimilation of information, which most students do not have.

The findings of this study indicate that the proposed tool can be used to accurately identify weak points in students' academic writing. We used criteria that can be explicitly interpreted referring to content, connective markers, argument structure and support for an argument, coherence and argumentative cohesion, word choice and wording, and these criteria were broken down into measurable components. In contrast to the tools reviewed above that have been used to examine writing skills among students in Israel and worldwide, this tool has excellent validity and reliability. Its explicit nature and the division into writing components reinforce its validity. Moreover, the fact that a sophomore student made perfect use of this tool to assess writing (her evaluation was validated by the researchers) indicates that any evaluator can use this tool, whether to assess writing or as an indicator for students themselves to improve their own writing. Using this tool, lecturers and students can assess themselves and improve whatever needs to be improved. The tool is user friendly and does not require any special expertise to use.

Because of the tool's accuracy, it is effective not only for assessing basic skills but also for higher-order skills. The tool can be used to distinguish and differentiate between a "shopping list" of ideas and a summary, and between a summary and textual expressions of information merged from a number of sources. A text that synthesizes information makes the relations 
and connections among the ideas explicit by means of connectors that express these relations, words of negation and words of addition (as in "in contrast" or "in addition"). These words explicitly connect ideas from different texts and constitute an important indicator of synthesis. Texts organized as lists of ideas or arguments lack such connective devices. Even if such lists refer to the text from which they were taken, the lack of explicit connectors between ideas or arguments points to writing that does not involve a merger of ideas. The research tool links between theories of information merging and practical implementation. It provides prompts for performing the merging task (q6), thus making it possible to identify those who use these prompts and those who do not find them meaningful because they have no previous experience in such a task. Perhaps most of the students who did not manage to identify the connections between the texts (as required in q6) did not notice the prompts suggested to them in this question, which were intended to help them perform the task. Hence, they summarized even though they were asked to merge information. The reason for this may be their lack of prior experience in information merging, which may have been a new and unfamiliar skill for them.

We hypothesized that the students would demonstrate a good command of summarization skills because summarization is part of the high school Hebrew studies curriculum (Ministry of Education, 2005: section on comprehension and expression). We therefore assumed that the students already had written summaries in high school. The high school curriculum also requires students to merge information from different texts, but these are usually not academic texts. Because we had no way of knowing how much opportunity students had to practice this skill, we could not hypothesize or predict their level of performance on writing tasks requiring the merging of information from a number of sources. This study examined students' actual level of performance and attempted to identify proficiency on a merging task based on three texts. The levels were ranked as follows: a sequential list of ideas, a combination of two main ideas from two texts, integration and synthesis of two texts, and comprehensive synthesis of all three texts. The following examples from the students' answers demonstrate these levels.

\subsection{Sequential List of Ideas}

In the first article A.B. Yehoshua argues that a Jew is someone who chooses to be a Jew. In the second article Y. Kaufman claims that a Jew is someone who was born Jewish. It is fate that determines who is a Jew and not a matter of individual choice. In the third article Amos Oz argues that a Jew is someone who has chosen to be a partner to the fate of other Jews or who was sentenced to this fate (q7, merging three articles, questionnaire 174).

In this example, the student presented the ideas from all three articles in his own words, but did not refer to the connections between the ideas, instead presenting them as a sequential list. In effect, this is one summary after another and not a merger of information from the three sources. 


\subsection{Integration of Ideas from Two Texts}

To be a Jew means to belong to a national group that one can join and leave (from A.B. Yehoshua), and a Jew is someone who identifies himself as a Jew. In addition, a Jew is someone who acknowledges his Jewishness in public ("To Be a Jew" by Amos $O z$ ) (q7, merging three articles, questionnaire 168).

In this example, the student presented ideas from two of the articles in his own words and gave expression to the connections between the ideas through the use of the phrase "in addition." Yet he only referred to two of the texts.

\subsection{Integration and Synthesis of Two Texts}

A Jew is someone who sees himself as a Jew (A.B. Yehoshua) and anyone who has been forced to be a Jew (Amos Oz, "To Be a Jew ") (q7, merging three articles, questionnaire 122).

This example demonstrates the integration and synthesis of the ideas from two articles into a single sentence that illustrates the associations between the ideas. The use of the conjunction "and" demonstrates this association of addition.

\subsection{Comprehensive Synthesis (Information Merger) to Create a New Text}

Amos $O z$ and A.B. Yehoshua both consider the term Jew to be an individual choice (even someone forced to be a Jew chooses to remain a Jew). They both attribute importance to this choice as a declaration of fate, and they both refer to the religious definition and to Jewish Law to demonstrate the other side of the coin. Yechezkel Kaufman, in contrast, relates to Judaism as a heritage that is not solely dependent on disasters such as the Holocaust for an individual to choose Judaism. Kaufman sees Judaism as a covenant and the Jews as the members of this covenant (q7, merging three articles, questionnaire 25).

In this example, the merged generalization is already apparent in the opening sentence, as is the way in which the relations and connections of ideas from the three articles develop into a paragraph that expresses the individual voice of the writer and his choices for presenting the information. The student combined the two similar ideas and expressed this twice in the text, first by mentioning the names of the two writers one after the other before stating their common or similar idea and then in the second sentence by using the word "both." The contrast between the two similar ideas and the idea from the third article is explicitly expressed through the negative word that anticipates the idea: "Yechezkel Kaufman, in contrast."

\section{Conclusions and Proposals}

This study found that most of the students succeeded on the tasks that required generation of coherence and content. They identified structured sentences as the main idea and then identified the supporting sentences. From this we can conclude that the students internalized the writing formats of summarization and argumentation from their studies in high school. 


\section{Mll Macrothink}

International Journal of Linguistics

ISSN 1948-5425

2013, Vol. 5, No. 4

This may be because they practiced this skill, as it is one of the requirements in the high school Hebrew studies curriculum.

Another clearly stated objective of this curriculum is merged summarization, which requires the skills of merging information, creating connections between ideas in a paragraph and expressing these connections in writing. Moreover, development of the higher-order skills of argumentative writing, classified summarization and logical structures and connectors is also explicitly noted in this curriculum. Despite this, most of the students did not exhibit proficiency on the merging task. This lack was particularly apparent in the task involving writing a merged paragraph. Only a few of the participants gave expression to the association between the ideas or the arguments made in the different texts by using suitable words of addition and contrast and by providing an explanation or example of this association.

These findings lead to the question of how to reduce this gap between the writing skills of entering freshman students and the skills required for academic writing. These skills of merging information from a number of sources and creating a synthesis of these ideas are not well known by most students in Israel and worldwide. We recommend devoting attention to this requirement, which is part of the high school Hebrew studies curriculum, as was successfully done for summarization skills. This should involve giving structured and graduated assignments that involve identifying the associations between ideas in three short texts (task 6 on the questionnaire) and practicing giving expression to these associations by writing a short paragraph (task 7). After that, the level of difficulty should be increased by adding additional texts. Allocating lessons to this topic in high school should help students successfully perform such tasks in college or university.

\section{References}

Bar-Asher, M. (2012). From reading to writing. Mayim midelav, 22-23, 11-23 [Hebrew].

Beaufort, A. (2007). College writing and beyond: A new framework for university writing instruction. Logan, UT: Utah State UP.

Brig, Y. (1994). Didactic implementation of discourse theory in teaching academic writing. Maof u'ma'aseh bamichlelet Achva, 1, 99-102 [Hebrew].

Brosh, S. (1996). Addressed to the Reader C. Ramat Aviv: Center for Educational Technology (CET) [Hebrew].

Brosh-Weitz, S. (1999). New Literacy from the Pedagogical Perspective: A Guide for the Teacher - Addressed to the Reader A, B and $C$. Ramat Aviv: Center for Educational Technology (CET) [Hebrew].

Cohen, L., Manion, L., \& Morrison, K. (2007). Research methods in education. New York: Routledge.

Cohen-Gross, D. (2003). Teaching writing in educational systems worldwide - trends and goals. Chelkat Lashon, 35, 65-75 [Hebrew].

Connor, U. M. (1984). A Study of Cohesion and Coherence in English as a Second Language 
Students' Writing. International Journal of Human Communication, 17, 301-316. http://dx.doi.org/10.1111/j.1467-9817.2010.01449.x

Coxhead, A. (2000) A New Academic Word List. TESOL Quarterly, 34, 213-238. http://dx.doi.org/10.2307/3587951

Cushing, W. S. (2004). Integrating reading and writing in a competency test for non-native speakers of English. Assessing Writing, 9(1), 27-55.

Dubarry, R. (2008). Colleges are taking over where high schools have failed: Trends in freshman writing. Helium. Retrieved from http://www.helium.com

Ezer, H., \& Ram, D. (1999). Assessing academic literacy. Mahalachim. Levinsky College of Education [Hebrew].

Ezer, H. (2002). Writing and its teaching - a procedural approach. In A. Vahal (ed.), Theoretical and practical reading, E (10). Tel Aviv: The Open University [Hebrew].

Ezer, H., Margolin, B. \& Sagi, R. (2009). Academic writing - Perceptions among education students and lecturers of its significance and role in a college of education, Research Report. Tel Aviv: Research \& Development Authority, Levinsky College of Education [Hebrew].

Flower, L. S. (1989). Problem solving strategies for writing. (3rd ed.). Chicago: Harcourt Brace Janovich. http://doi.org/10.1017/S0142716400006251

Folman, S. (1997). In the circles of pedagogical theory: From text that is read to text that is written. Even Yehuda: Rickless [Hebrew].

Folman, S. (Ed.) (1994). Should theoretical literacy be taught at institutions of higher education in a basic and methodological course, and if not, how should this knowledge be imparted? (abstracts from a panel discussion). Chelkat lashon, 24, 120-135 [Hebrew].

Graesser, A. C., McNamara, D. S., Louwerse, M. M., \& Cai, Z. (2004). Coh-Metrix: Analysis of text on cohesion and language. Behavior Research Methods, Instruments, \& computers, 36(2), 193-202.

Halliday, M. A. K., \& Hasan, R. (1976). Cohesion in English. London: Longman.

Hamp-Lyons, L. (1991). Scoring procedures for ESL contexts. In L. Hamp-Lyons (Ed.), Assessing second language writing in academic contexts (pp. 241-276), Norwood, NJ: Albex. http://dx.doi.org/10.1016/S1060-3743(03)00016-X

Hauftman, S., Rosenfeld, M., \& Tamir, R. (1999). "Model for reading and writing" in the process of producing an academic text. Maof u'ma'aseh bamichlelet Achva, 5, 23-60 [Hebrew].

Hazlett, C. (2008). A review: Beaufort, Anne. College writing and beyond: A new framework for university writing instruction. Logan, UT: Utah State UP, 2007. 242pp. Composition Forum, 18, Summer 2008. Retrieved Sep. 5, 2009, from http://compositionforum.com/issue/18/ 


\section{$\triangle$ Macrothink}

International Journal of Linguistics ISSN 1948-5425

Hilsdon, J. (2004). From 'fuzzy' to 'functional' - along the way to 'critical': A first year journey in Higher Education? University of Plymouth. March 2004. Retrieved from http://www.fyhe.qut.edu.au.

Kiuhara, S. A., Graham, S., \& Hawken, L. S. (2009). Teaching writing to high school students: A national survey. Journal of Educational Psychology, 101(1), 136-160. http://dx.doi.org/10.1037/a0014883

Knoch, U. (2008). The assessment of academic style in EAP writing: The case of the rating scale. Melbourne Papers in Language Testing, 13(1), 34-67.

Kroll, B. (1979). Freshmen college composition: Description of the examination. ELT Journal, 33(3), 219-227.

Kroll, B. (1998). Assessing writing abilities. Annual Review of Applied Linguistics 18, 219-240. http://dx.doi.org/10.1017/S0267190500003536

Lee, M. (1994). "I thought I could write until I came here": Student writing in higher education, in Gibbs, G. (Ed.). Improving student learning: Theory and practice. Oxford: Oxford Centre for Staff Development.

Margolin, B. (2012). Towards a Description of Coherence Patterns in Contemporary Hebrew Prose and Palestinian-Israeli Arabic Prose. Intercultural Pragmatics, 3(9), 293-308.

Margolin, B., \& Ezer, H. (2008). Intercultural Discourse Patterns in Writing Argumentative Texts: A Comparison of Texts Written by Jewish and Arab Student- Teachers. ITL Special Issue on Learning and Teaching L2 Writing, 156, 153-168.

McNamara, D. S., Louwerse, M. M., McCarthy, P. M., \& Graesser, A. C. (2010). Coh-Metrix: Capturing linguistic features of cohesion. Discourse Processes, 47, 292-330.

Ministry of Education. (2005). Curriculum: Hebrew for State and State-Religious High Schools [Hebrew].

Rafaeli, R. (1996). Writing an article in the argumentative style. Egeret media: Yediat halashon, haba'a vehavanat hanikra, 43, 40-52 [Hebrew].

Sarel, Z. (1997). The discourse of exposition and the discourse of argumentation in fostering academic literacy. Dapim, 25, 66-83 [Hebrew].

Sarig, G. (1997). Merging information from several sources. In G. Sarig, \& S. Folman (Eds.), Principles and practices in teaching reading (pp. 349-371). Tel Aviv: Open University [Hebrew].

Scardamalia, M., Bereiter, C., \& Goelman, H. (1982). The role of production factors in writing ability. In M. Nystrand (Ed.), What writers know: The language, process and structure of written discourse. New York: Academic Press. pp. 173-210.

Segev-Miller, R. (1999). On the use of intertextual strategies in the process of merging information. Hahinuch vesevivo, 21, 159-175 [Hebrew]. 
Shen, Y. (2010). Qualitative Characteristics of Coherence, Substitution, and Reference by Non-English Major Chinese Students. English Language Teaching, 3(2), 104-114.

Shilo, G. (2003). Understanding and writing texts. Even Yehuda: Rickless [Hebrew].

Smagorinsky, P., \& Smith, M. W. (1992). The nature of knowledge in composition and literary understanding: The question of specificity. Review of Educational Research, 62(3), 279-305.

Steinway, C. (2008). Not all freshmen are ready for college writing. The Tufts Daily: Tufts University.

Sufumi, S. (2002). The form-meaning interface: A study of Japanese as a foreign-language writing. In J. A. Hammadou Sullivan (Ed.), Literacy and the second language learner. Research in second language learning (pp. 11-131). Greenwich, CT: Information Age Publishing.

Tanskanen, S. K. (2006). Collaborating towards Coherence: Lexical Cohesion in English Discourse. Amsterdam/ Philadelphia: John Benjamins Publishing Company.

Van Dijk, T. A. (2008). Discourse and Context: A socio cognitive approach. Cambridge: University press.

Van Dijk, T. A. \& Kintsch, W. (1983). Strategies of discourse comprehension. New York: Academic Press.

Yarchi, R. (2001). Academic writing level among college students at the end of their first year of studies - research report. Dapim: Journal of theory and research in teacher training, 32, 106-130 [Hebrew].

Zhao, C. G., \& Llosa, L. (2008). Voice in high-stakes L1 academic writing assessment: Implications for L2 writing instruction. Assessing Writing, 13(3), 153-170.

\section{Appendixs}

Appendix 1. Test of Academic Writing Skills (TAWS)

We seek to examine your writing skills in order to adapt the Academic Literacy course to your needs. We thank you in advance for your cooperation.

Please complete the following information:

Age:

Country of birth: Date of immigration:

Mother tongue:

Major area of studies: Early Childhood / Elementary / High School / Special Education / Combined Major / Music / Cross-Disciplinary / Excellence Program

Other: 


\section{IIMacrothink}

International Journal of Linguistics

ISSN 1948-5425

2013, Vol. 5, No. 4

During your previous studies, were you eligible for accommodations, such as extra time?

\section{Read the article "Who is a Jew?" by A.B. Yehoshua.}

1. Find the main idea in the text "Who is a Jew?" by A.B. Yehoshua and copy it.

2. Copy two other important ideas from the text "Who is a Jew?" by A.B. Yehoshua.

3. The text "Who is a Jew?" by A.B. Yehoshua contains examples. Quote one example.

4. Find six connecting words in the text "Who is a Jew?" by A.B. Yehoshua and copy them.

5. In your own words, summarize the article "Who is a Jew?" by A.B. Yehoshua. Write a single paragraph with 5-6 lines.

Read the three articles: "Who is a Jew?" by A.B. Yehoshua; "To Be a Jew" by Amos Oz; and "Judaism is..." by Yechezkel Kaufman.

1. What kinds of associations or links are there among the three texts you read: addition? contrast? similarity?

2. In your own words, write a single paragraph of 5-6 lines that merges the three articles you read into a single paragraph. Add references to the texts you talk about.

Appendix 2. Encoding Key

Test Number:

\begin{tabular}{|l|l|l|l|l|l|}
\hline & & & $\begin{array}{l}\text { To a } \\
\text { small } \\
\text { extent } \\
\text { (2) }\end{array}$ & $\begin{array}{l}\text { To a } \\
\text { large } \\
\text { extent } \\
\text { (3) }\end{array}$ & $\begin{array}{l}\text { Very } \\
\text { much } \\
\text { (4) }\end{array}$ \\
\hline $\begin{array}{l}\text { Question 1: Find the } \\
\text { main idea in the text } \\
\text { "Who is a Jew?" by } \\
\begin{array}{l}\text { A.B. Yehoshua and } \\
\text { copy it. }\end{array}\end{array}$ & & & & & \\
\hline $\begin{array}{l}\text { Question 2: Copy } \\
\text { two other important } \\
\text { ideas from the text } \\
\text { "Who is a Jew?" by } \\
\text { A.B. Yehoshua. }\end{array}$ & & & & & \\
\hline $\begin{array}{l}\text { Question 3: The text } \\
\text { (3.1 Identification }\end{array}$ & & & & & \\
\hline
\end{tabular}


"Who is a Jew?" by A.B. Yehoshua

3.2 Format contains examples.

Quote one example.

Question 4: Find 6 connecting words in the text "Who is a Jew?" by A.B.

Yehoshua and copy them.

Question 5: In your own words, summarize the article "Who is a Jew?" by A.B. Yehoshua. Write a single paragraph with 5-6 lines.

\begin{tabular}{|l|} 
\\
\hline $\begin{array}{l}\text { Question 6: What } \\
\text { kinds of associations } \\
\text { or links are there } \\
\text { among the three } \\
\text { texts you read? }\end{array}$ \\
\hline $\begin{array}{l}\text { Question 7: In your } \\
\text { own words, write a } \\
\text { single paragraph of } \\
\text { 5-6 lines that merges } \\
\text { the three articles you } \\
\text { read into a single } \\
\text { paragraph. Add } \\
\text { references to the }\end{array}$ \\
\hline
\end{tabular}

5.1 Formal structure

Correctness

Punctuation

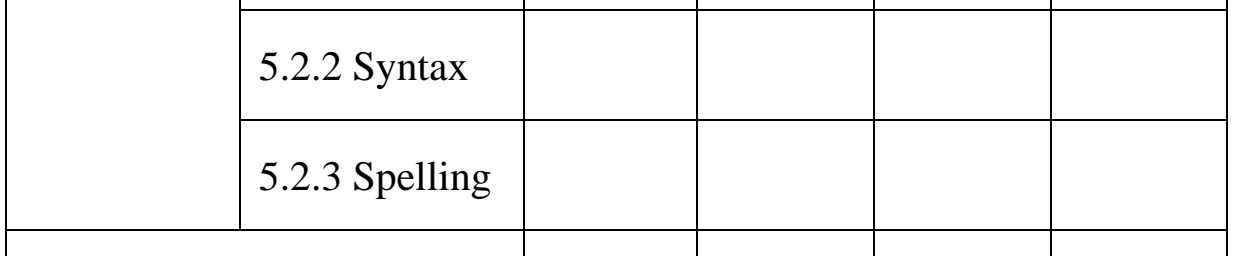

5.3 Coherence

5.4 Cohesion

5.5 Style

\subsection{Formal structure}

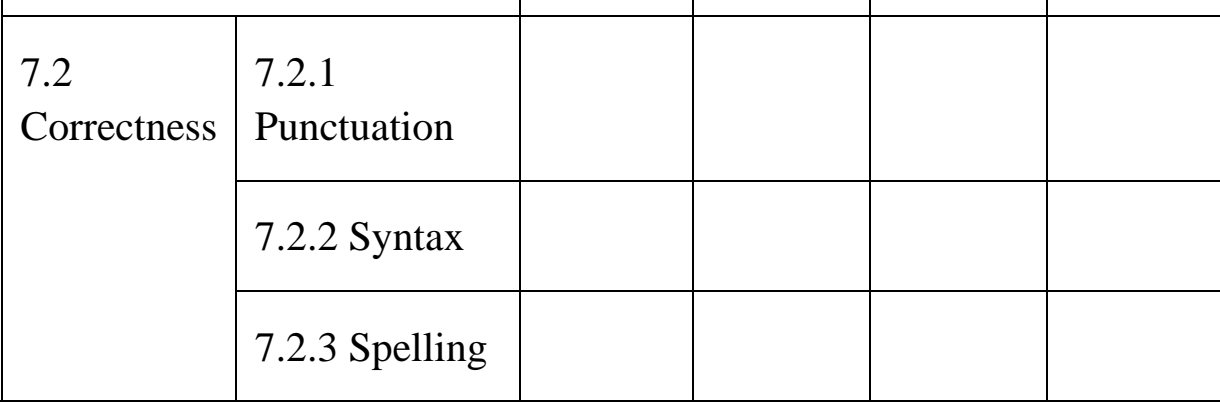




\begin{tabular}{|l|l|l|l|l|l|}
\hline texts you talk about. & 7.3 Coherence & & & & \\
\cline { 2 - 6 } & 7.4 Cohesion & & & & \\
\cline { 2 - 6 } & 7.5 Style & & & & \\
\cline { 2 - 6 } & 7.6 References & & & & \\
\hline
\end{tabular}

